Check for updates

Cite this: Nanoscale Adv., 2019, 1, 2029

\section{Synthesis of nanostructured catalysts by surfactant-templating of large-pore zeolites $\dagger$}

\author{
Aqeel Al-Ani, (D)*ab Josiah J. C. Haslam, (D) a Natalie E. Mordvinova, (D) \\ Oleg I. Lebedev, (D) ${ }^{c}$ Aurélie Vicente, (D) ${ }^{d}$ Christian Fernandez (D) ${ }^{d}$ \\ and Vladimir Zholobenko (D) *a
}

\begin{abstract}
Zeolites and related crystalline molecular sieves are utilised in a wide range of reactions and processes due to their regular microporous structure, strong acidity, shape selectivity and ion-exchange properties. However, their practical applications can be limited by the small size of the channels and cavities of the microporous structures, and therefore, a great deal of effort has been devoted to enhancing the transport of large-sized molecules in the host pores. Several commercially available zeolites, including faujasite (FAU), mordenite (MOR), beta (BEA), ZSM-5 (MFI) and zeolite L (LTL), have been exposed to a variety of acid and base treatments in the presence of a surfactant (cetyltrimethyl ammonium bromide, CTAB), which led to the controlled introduction of intracrystalline mesoporosity. The detailed characterisation of the obtained mesostructured zeolites has been carried out using FTIR spectroscopy, high resolution TEM, XRD, $\mathrm{N}_{2}$ adsorption, ${ }^{29} \mathrm{Si}$ and ${ }^{27} \mathrm{Al}$ MAS NMR. This work demonstrates a successful application of the supramolecular templating approach for generating tuneable mesoporosity in a range of zeolites possessing 12-membered ring channels, which has been applied to zeolite $L$ for the first time, thus producing hierarchical meso-microporous materials with improved accessibility of active sites and enhanced catalytic performance in dealkylation of tri-isopropylbenzene.
\end{abstract}

Accepted 27th February 2019

DOI: 10.1039/c9na00004f

rsc.li/nanoscale-advances
Received 3rd January 2019

\section{Introduction}

Zeolites are crystalline microporous materials with well-defined structures built of corner-sharing $\mathrm{SiO}_{4}$ and $\mathrm{AlO}_{4}$ tetrahedral units, which are linked by oxygen atoms that create a variety of channels and cages, which are highly uniform in size and shape. As the dimensions of the channels are such that they adsorb molecules of a certain size, these materials are known as molecular sieves and are widely used in a variety of applications, including separation, adsorption and selective catalysts. ${ }^{1,2}$ The reported zeolite pore topologies of interest in catalysis are formed by $1 \mathrm{D}, 2 \mathrm{D}$ or $3 \mathrm{D}$ pore structures with the pores typically comprising 8- (small pores), 10- (medium pores) or 12- (large pores) membered rings (MR). Some of the active sites located inside these pores, especially in the small and medium channels, are not accessible because of diffusional limitations and size exclusion, which can lead to poor performance of zeolite

${ }^{a}$ School of Chemical and Physical Sciences, Keele University, Keele, Staffordshire, ST5 5BG, UK. E-mail: a.a.t.al-ani@keele.ac.uk; v.l.zholobenko@keele.ac.uk

${ }^{b}$ Oil Marketing Company (SOMO), Baghdad, Iraq

'Laboratoire CRISMAT, ENSICAEN, UMR CNRS 6508, 6 Boulevard du Maréchal Juin, 14050, Caen Cedex 04, France

${ }^{d}$ Normandie Univ, ENSICAEN, UNICAEN, CNRS, Laboratoire Catalyse et Spectrochimie, 14000 Caen, France

$\dagger$ Electronic supplementary information (ESI) available. See DOI: 10.1039/c9na00004f catalysts, pore blockage and active site deactivation. ${ }^{3-7}$ An alternative solution to address this issue is by preparing mesoporous MCM-41 and SBA-15-type materials with a 1.5-30 nm pore range that could overcome some of the limitations associated with zeolites. However, these materials exhibit weak acidity, lack of hydrothermal stability and low crystallinity. ${ }^{4}$ At the same time, sustained efforts have been devoted to designing nano-sized zeolite crystals aiming to reduce the diffusion path length, although, this approach may have limited large-scale applications due to the high costs and practical difficulties associated with handling and separating such materials from the crystallisation mixtures. ${ }^{2,7}$ In recent years, a number of strategies have been introduced in the field of the synthesis of well-defined hierarchical zeolites containing micro-, meso- and macro-pores, such as the so-called bottom-up and top-down approaches. ${ }^{4-19}$ These approaches for improving the accessibility of active sites and transport efficiency rely upon the presence of a hierarchy of pores in the zeolite crystals, which are referred to as mesostructured or hierarchical zeolites. The bottom-up procedure is based on employing either hard or soft templates, such as carbon nanotubes, polymers, and organic structure directing agents to generate secondary mesopores in the range $2-50 \mathrm{~nm}$. The main disadvantages of this strategy are the high cost of the template and some difficulties in removing the organic species after the hydrothermal synthesis, which might affect the degree of structural order in the resulting 
material. The second strategy involves post-synthesis dealumination or desilication of zeolite crystals utilising, for instance, chemical etching and steaming. Among them, although this strategy is a destructive approach that often generates extra framework fragments with ineffective pore size control, the surfactant-templated mesostructuring approach has been successfully commercialised. ${ }^{20-23}$

In the present contribution, zeolites with different structures and chemical compositions are treated with a long-chain alkyl quaternary amine cationic surfactant at controlled $\mathrm{pH}$ in order to generate an intracrystalline network of mesopores without causing excessive degradation of the zeolite structure, and therefore, reduce transport limitations in the reaction involving larger molecules. ${ }^{22}$ To evaluate the efficiency of the mesostructuring process in the zeolites with different structures and $\mathrm{Si} / \mathrm{Al}$ ratios, extensive development work has been focused on the preparation of hierarchical FAU, BEA, MOR, LTL and ZSM-5 zeolites by surfactant-templating. The detailed characterisation of the parent and modified mesostructured zeolites was carried out using XRD, $\mathrm{N}_{2}$ physisorption, solid-state NMR, and TEM as well as FTIR spectroscopy.

\section{Experimental section}

\subsection{Synthesis of hierarchical zeolites}

Several series of hierarchical materials were prepared from the parent FAU, BEA, MOR and MFI and LTL zeolites generally by utilising a one-step procedure to introduce mesoporosity into these materials. A base or an acid was used to initiate either desilication or dealumination of the zeolite in the presence of a cationic surfactant under controlled conditions. The samples were washed, dried, and calcined at elevated temperatures prior to the structural characterisation. The obtained mesostructured zeolites were denoted as M-Zeolite$i$, where $i$ refers to the extent or severity of the mesostructuring treatment, which would depend on the concentration of the acid or base and the temperature and duration of the modification procedures.

Faujasite. Na-Y zeolite (FAU structure type, CBV100, Si/Al = 2.6) was purchased from Zeolyst International and modified to obtain the hierarchical zeolite, following the procedure adapted from ref. 24. In a typical preparation, $5.0 \mathrm{~g}$ of the commercial faujasite was mixed with $50 \mathrm{~mL}$ of water and the $\mathrm{pH}$ of the slurry was adjusted to $\sim 5.5-5.7$ using few drops of dilute nitric acid (Fisher Scientific, 70\%). Then the slurry was stirred with $10 \%$ citric acid (Fisher Scientific, 99.9\%) using 1.5-9.0 milliequivalents of the acid per $1 \mathrm{~g}$ of the zeolite for $1 \mathrm{~h}$ at ambient temperature. After centrifuging and rinsing with deionised water, the acid treated material was recovered and dried for $1 \mathrm{~h}$ at room temperature. The zeolite was re-slurried in a solution containing $0.12-0.75 \mathrm{~g}$ of sodium hydroxide (Fisher Scientific, 99\%) and $2.60 \mathrm{~g}$ of $n$-hexadecyltrimethylammonium bromide (CTAB) (Alfa Aesar, 98\%). The mixture was kept at $80-100{ }^{\circ} \mathrm{C}$ for $24 \mathrm{~h}$. Next, the solid was recovered, washed and dried overnight. To remove the template, $\sim 2 \mathrm{~g}$ of the sample was calcined in a tube furnace in a flow of nitrogen at $450{ }^{\circ} \mathrm{C}$ (temperature ramp of $1.5{ }^{\circ} \mathrm{C} \mathrm{min}^{-1}$ ) for 1 hour and then in oxygen at $550{ }^{\circ} \mathrm{C}$ (temperature ramp of $2{ }^{\circ} \mathrm{C} \min ^{-1}$ ) for 2 hours. Prior to the FTIR and reaction studies, the sample was three-fold ion-exchanged using $1 \mathrm{~mol} \mathrm{~L}^{-1}$ ammonium nitrate solution.

Mordenite and beta zeolites. The MOR (Zeolyst, CBV 21A, $\mathrm{Si} / \mathrm{Al}=10$ ) and BEA (Zeolyst, CP814E Si/Al = 12.5, CP814C Si/ $\mathrm{Al}=19$, and $\mathrm{CP} 811 \mathrm{C}-300, \mathrm{Si} / \mathrm{Al}=150$ ) zeolites were modified according to the procedure reported in ref. $25.2 \mathrm{~g}$ of parent MOR or BEA zeolites was calcined in a muffle furnace in air at $450{ }^{\circ} \mathrm{C}$ for $3 \mathrm{~h}$, cooled to room temperature and then stirred in $50 \mathrm{~mL}$ of a basic solution of $0.13-0.5 \mathrm{~mol} \mathrm{~L}^{-1}$ tetramethylammonium hydroxide pentahydrate TMAOH (Alfa Aesar, 98\%). Next, 1-1.85 $\mathrm{g}$ of CTAB was added to this mixture. After $1 \mathrm{~h}$, the synthesis mixture was placed into a Teflon-lined autoclave and heated to $150{ }^{\circ} \mathrm{C}$ using a CEM Mars 6 microwave. The heating time was varied from $5 \mathrm{~h}$ to $18 \mathrm{~h}$. The initial ramp time was 20 minutes and the power output was limited to $400 \mathrm{~W}$. The product was filtered and washed with deionized water, dried overnight and calcined in a flow of nitrogen at $400{ }^{\circ} \mathrm{C}$ (temperature ramp of $1.5{ }^{\circ} \mathrm{C} \mathrm{min}^{-1}$ ) for $1 \mathrm{~h}$ and oxygen at $500{ }^{\circ} \mathrm{C}$ (temperature ramp of $2{ }^{\circ} \mathrm{C} \mathrm{min}^{-1}$ ) for $2 \mathrm{~h}$.

ZSM-5 zeolite. The parent MFI (Zeolyst, CBV 3024E Si/Al = 15, CBV 5524G Si/Al = 25, and CBV $8014 \mathrm{Si} / \mathrm{Al}=40$ ) zeolites were treated with $50 \mathrm{~mL}$ of a basic solution containing $0.2 \mathrm{~mol}$ $\mathrm{L}^{-1}$ of sodium hydroxide and tetrapropylammonium hydroxide TPAOH (Alfa Aesar, $1 \mathrm{~mol} \mathrm{~L}^{-1}$ ). $1 \mathrm{~g}$ of CTAB was added to this mixture and stirred for $1 \mathrm{~h}$ at $80{ }^{\circ} \mathrm{C}$. This protocol followed the desilication method described in ref. 26. The resulting mixture was treated at $150{ }^{\circ} \mathrm{C}$ using microwave irradiation for 8 to $16 \mathrm{~h}$, according to the method described above. The zeolite was filtered, washed and dried at room temperature. The dried zeolite was subjected to a threefold ion-exchange with $0.5 \mathrm{~mol} \mathrm{~L}^{-1}$ ammonium nitrate solution at $60^{\circ} \mathrm{C}$ for $1 \mathrm{~h}$. Finally, the product was filtered, washed, dried overnight and then calcined using the method described for $\mathrm{Na}-\mathrm{Y}$.

Zeolite L. $3 \mathrm{~g}$ of NaK-LTL zeolite (Tosoh, HSZ-500KOA, Si/Al = 3.2) was slurried in $11 \mathrm{~g}$ of deionised water and treated with 0.2$0.4 \mathrm{~mol} \mathrm{~L}^{-1}$ of sulphuric acid (Fisher Scientific, 70\%) for $1 \mathrm{~h}$. The treated zeolite was then filtered and washed with hot deionised water. The dealuminated zeolite was re-slurried in $20 \mathrm{~g}$ of water and the $\mathrm{pH}$ of the slurry was adjusted to 7.0 using a sodium hydroxide solution. The slurry was then treated with $0.1-0.2 \mathrm{~g}$ of $50 \mathrm{wt} \%$ sodium hydroxide in the presence of $1.40 \mathrm{~g}$ of CTAB at 80 $100{ }^{\circ} \mathrm{C}$ overnight. The solid product was isolated and three-fold ion-exchanged with $0.5 \mathrm{~mol} \mathrm{~L}^{-1}$ ammonium nitrate solution at 40 ${ }^{\circ} \mathrm{C}$ for $1 \mathrm{~h}$. Next, the zeolite was filtered, washed, dried at room temperature and calcined using the method described for MOR.

\subsection{Characterisation of hierarchical zeolites}

Comprehensive structural characterisation of all the materials utilised in this work was carried out using powder X-ray diffraction (XRD) patterns which were recorded on a Bruker D8 Advance diffractometer with $\mathrm{CuK}_{\alpha}$ radiation at $40 \mathrm{kV}$ and $40 \mathrm{~mA}$ over the 2theta angle range of $5-60^{\circ}$. In addition, mesostructured catalysts were characterised in the low 2-theta angle range between 1 and $13^{\circ}$ using a low scan rate. The crystalline phases were matched by 
comparing the XRD patterns of the catalysts with those reported in the literature. The relative crystallinity of the mesostructured materials was determined using Bruker EVA software. In addition, TM3000 (Hitachi) scanning electron microscopy (SEM) with energy dispersive X-ray analysis (EDX, Bruker) was utilised to obtain the elemental composition of the zeolites. The apparent surface area of the catalysts was calculated using the BET model for the $P / P_{0}$ relative nitrogen pressure $<0.04$; their micro- and mesopore volume and the pore size distribution were computed using the nonlinear density functional theory (NLDFT) model applied to the adsorption branch of the isotherms obtained from the nitrogen adsorption experiments carried out on a Quantachrom Autosorb instrument. The textural data were scaled to the mass of the activated samples, which was determined by thermogravimetric analysis (TGA). The TGA analysis was carried out in flowing nitrogen using a Rheometric Scientific STA 1500 instrument; the sample weight change was measured as a function of temperature (ramped from 20 to $500{ }^{\circ} \mathrm{C}$ at $10{ }^{\circ} \mathrm{C} \mathrm{min}{ }^{-1}$ ). Further details are available in ref. 24 .

TEM experiments were carried out using a FEI Tecnai G2 30 UT $\mathrm{LaB}_{6}$ microscope operating at $300 \mathrm{kV}$ and having $0.17 \mathrm{~nm}$ point resolution. Weak beam conditions were used for TEM experiments in order to prevent the degradation and artefacts in the samples. TEM samples were prepared by dispersing them in ethanol and transferring the dispersion onto a $\mathrm{Cu}$ holey carbon grid.

Solid-state NMR experiments were performed using a 500 $\mathrm{MHz}$ Bruker Advance III spectrometer operating at a Larmor frequency of $130.3 \mathrm{MHz}$ for ${ }^{27} \mathrm{Al}$ and $99.3 \mathrm{MHz}$ for ${ }^{29} \mathrm{Si}$. Powdered samples were packed into $4 \mathrm{~mm}$ rotors. For ${ }^{27} \mathrm{Al}$ MAS NMR, spectra were acquired using a relatively short pulse length of $1 \mu$ s (i.e., a selective pulse of $10^{\circ}$ ), a recycle delay of $1 \mathrm{~s}$ and a spinning rate of $14 \mathrm{kHz}$. For ${ }^{29} \mathrm{Si}$ MAS NMR, spectra were acquired using a $30^{\circ}$ pulse, a recycle delay of $20 \mathrm{~s}$ and a spinning rate of $12 \mathrm{kHz}$. Chemical shifts were referenced to $1 \mathrm{~mol} \mathrm{~L}^{-1}$ $\mathrm{Al}\left(\mathrm{NO}_{3}\right)_{3}$ for ${ }^{27} \mathrm{Al}$ and to TMS for ${ }^{29} \mathrm{Si}$.

Comparative characterization of the Brønsted and Lewis acid sites in zeolites was carried out using transmittance FTIR measurements in the $6000-900 \mathrm{~cm}^{-1}$ spectral range utilising pyridine adsorption. FTIR transmittance measurements were performed at $\sim 80{ }^{\circ} \mathrm{C}$ using catalyst self-supported disks activated in an in situ IR cell at $450{ }^{\circ} \mathrm{C}$ for $5 \mathrm{~h}$ in a vacuum $\left(10^{-5}\right.$ torr, a temperature ramp of $\left.1{ }^{\circ} \mathrm{C} \mathrm{min}^{-1}\right)$. FTIR spectra were collected using a Thermo is10 spectrometer at a $4 \mathrm{~cm}^{-1}$ resolution $\left(0.96 \mathrm{~cm}^{-1}\right.$ data spacing). The spectra were analysed using specialised Thermo software, Omnic. An excess of Py was admitted into the transmittance cell at $150{ }^{\circ} \mathrm{C}$, in a stepwise manner until no changes were observed in the spectra. The saturated sample was then evacuated for $20 \mathrm{~min}$ at $150{ }^{\circ} \mathrm{C}$ to remove physically adsorbed Py. The following values of the molar absorption coefficients were applied for Brønsted acid sites, BAS, $\varepsilon(\mathrm{BAS}, \mathrm{MFI})=1.08, \varepsilon(\mathrm{BAS}, \mathrm{BEA})=$ 1.16 , and $\varepsilon(\mathrm{BAS}, \mathrm{MOR})=1.34$, and $\varepsilon(\mathrm{BAS}, \mathrm{FAU}$ and LTL $)=1.65$ $\mathrm{cm} \mathrm{mol}{ }^{-1}$ (IR peak at $\sim 1545 \mathrm{~cm}^{-1}$ ) and for Lewis acid sites, LAS, $\varepsilon($ LAS $)=1.71 \mathrm{~cm} \mathrm{~mol}^{-1}$ (IR peak at $\sim 1455 \mathrm{~cm}^{-1}$ ). The error margin for the acid site quantification was estimated to be $\pm 5 \%$.

\subsection{Reaction studies}

The catalytic studies, utilising 1,3,5-tri-isopropylbenzene (TIPB, Sigma-Aldrich, $>95 \%$ ) dealkylation as a reaction test, were carried out in a conventionally heated high-pressure Monowave-50 reaction system (Anton Paar) using specially designed $10 \mathrm{~mL}$ glass vials as batch reactors operating at elevated temperature and pressure. In a typical reaction run, $0.2 \mathrm{~g}$ of the zeolite catalyst was activated in an open reactor at $400{ }^{\circ} \mathrm{C}$ for $5 \mathrm{~h}$, cooled down to $\sim 100{ }^{\circ} \mathrm{C}$ and then mixed with $2 \mathrm{~mL}$ of TIPB. The reactor was purged with nitrogen and sealed, and the temperature was raised to $240{ }^{\circ} \mathrm{C}$ and kept for $1 \mathrm{~h}$. Next, the reaction mixture was cooled down to $\sim 0{ }^{\circ} \mathrm{C}$ and the liquid products were isolated and analysed using GC-MS (see Table S1 in the ESI $\dagger$ ). From the repeated experiments, the estimated error of the conversion measurements was $\pm 2 \%$.

\section{Results and discussion}

XRD measurements have been performed in this study in order to monitor structural changes in the zeolites treated with acids or bases of different concentrations (Fig. 1-3 and S1, ESI $\dagger$ ). It is important to note that the apparent decrease in crystallinity with increasing severity of the treatment conditions, as evidenced by the intensity of the XRD patterns, can be due to two factors: the structural degradation of the "over-treated" zeolites and the intracrystalline mesoporosity introduced as the result of such treatment. XRD analysis reveals that the mesostructured zeolites maintain significant crystallinity following their treatment under relatively mild conditions; however, it decreases significantly with increasing severity of the acid or base treatment. This suggests that the introduction of mesopores can be achieved without a significant loss of crystallinity, which is in accord with previous reports. ${ }^{21,25-29}$ The results of low angle XRD measurements (Fig. 2a, 3a and c) also demonstrate some level of ordered pore arrangement in the mesostructured zeolites. In the three series of materials prepared from the parent zeolites $\mathrm{Y}$, MOR and $\mathrm{L}$, the intense peaks in the low 2-theta range (not detected in the parent zeolites) can be indicative of the lamellar or hexagonal ordering of the mesopores: at $2.5^{\circ}(d$-spacing $\sim$ $3.47 \mathrm{~nm}$ ) for mesostructured zeolite $\mathrm{Y}$, at $2.23^{\circ}$ ( $d$-spacing $\sim 3.95$ $\mathrm{nm}$ ) and $4.03^{\circ}(d$-spacing $\sim 2.18 \mathrm{~nm})$ for mesostructured mordenite, and at $2.0^{\circ}(d$-spacing $\sim 4.39 \mathrm{~nm})$ and $4.02^{\circ}(d$-spacing $\sim$ $2.19 \mathrm{~nm}$ ) for mesostructured zeolite L. However, no significant long-range ordering has been detected in zeolites BEA and ZSM5 after this treatment. This is an important observation indicating that there is a direct link between the zeolite micropore size and the formation of the intracrystalline mesopores. It can be suggested that the presence of 12-MR pores in the zeolite framework (Table 1), which are accessible to the surfactant species, would facilitate the formation of regular mesopores during the surfactant-templated mesostructuring process. In contrast, the 10-MR channels of the medium pore ZSM-5 zeolite would be largely inaccessible for the surfactant. Thus, there is no long-range ordering observed in the treated ZSM-5. With regard to the BEA zeolite, there is no conclusive evidence for the long-range ordering of the mesopores, which may be related to 
(a)

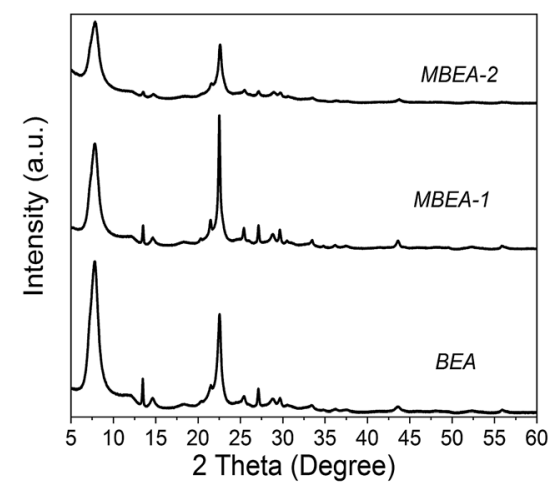

(b)

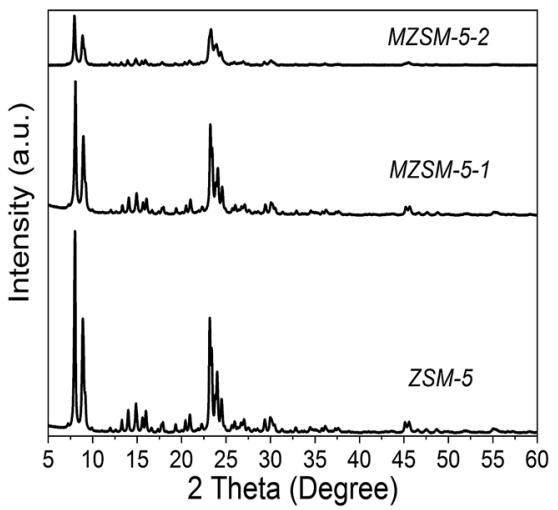

Fig. 1 XRD patterns of the parent and treated BEA (a) and ZSM-5 (b) zeolites.

(a)

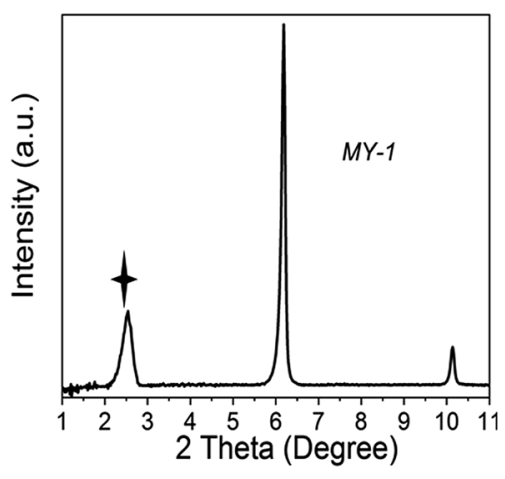

(b)

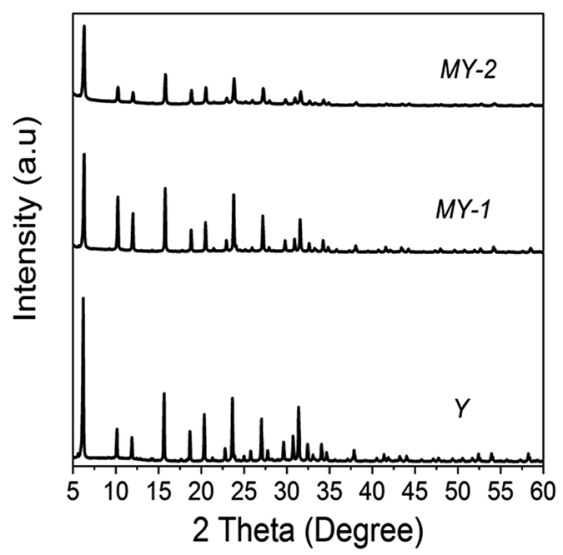

Fig. 2 Low-angle (a) and wide-angle (b) XRD patterns of the parent and treated Y zeolites. The starred peak indicates long-range ordering in the mesostructured sample.

the complexity of its structure. Zeolite beta consists of two distinct polymorphs, A and B. ${ }^{30}$ The XRD patterns of the commercial BEA samples utilised in this work correspond to materials comprising $\sim 50 \%$ of polymorph A and $50 \%$ of polymorph B. $^{31}$ The polymorphs intergrow as two-dimensional sheets that randomly alternate forming a three-dimensional framework with a 3D network of 12-MR pores. The intergrowth of the polymorphs does not significantly affect the pores in two of the dimensions, but in the direction of the faulting, the pores become tortuous, which may restrict the access of surfactant species during the mesostructuring treatment. In addition, the random nature of the intergrowth would prevent the formation of ordered mesopores within the BEA structure.

An important insight into the formation of mesostructured zeolites comes from high-resolution TEM (HRTEM) imaging (Fig. 4). For the parent zeolites, particularly Na-Y, TEM data demonstrate the nano-scale features of well-crystallised materials with sub-micron particle size. It appears that for the BEA sample, large zeolite particles $(\sim 600 \mathrm{~nm})$ consist of agglomerates of single crystals about $40-50 \mathrm{~nm}$ in size, which is in agreement with the dimension of crystalline domains ( $\sim 40$ $\mathrm{nm}$ ) estimated from the line broadening in the XRD patterns using the Scherrer equation. The high resolution images demonstrate the presence of intracrystalline mesopores, confirming that the surfactant-templated mesostructuring procedure was successful for large-pore zeolites. The pore size in faujasite and BEA zeolites (Fig. 4a and b) ranges from 10 to 15 $\mathrm{nm}$ and from 5 to $8 \mathrm{~nm}$, respectively. In the samples of MOR and LTL zeolites (Fig. 4c and 5 respectively), the pore size is significantly smaller, $3-5 \mathrm{~nm}$, in agreement with the nitrogen adsorption data. Furthermore, arrays of parallel mesopores are observed for the latter two zeolites, which would correspond to the long-range order peaks detected in the XRD patterns at $\sim 2^{\circ}$ ( $d$-spacing of $\sim 4 \mathrm{~nm}$ ). In agreement with previous reports, ${ }^{21,24,32}$ the generated mesopores are clearly located in the MOR zeolite crystals, confirming that a single step rearrangement process takes place during the mesostructuring of a large-pore zeolite in the presence of the cationic surfactant under mildly basic treatment conditions in contrast to the recrystallisation procedure, involving partial destruction and reassembly under more severe conditions. Interestingly, in the case of LTL zeolite (Fig. 5), mesopores are located in the exterior layer of the LTL 
(a)

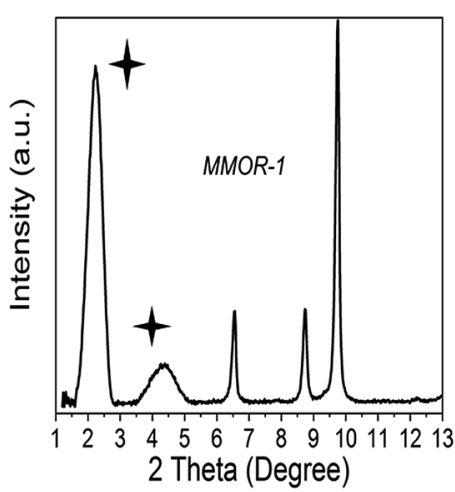

(c)

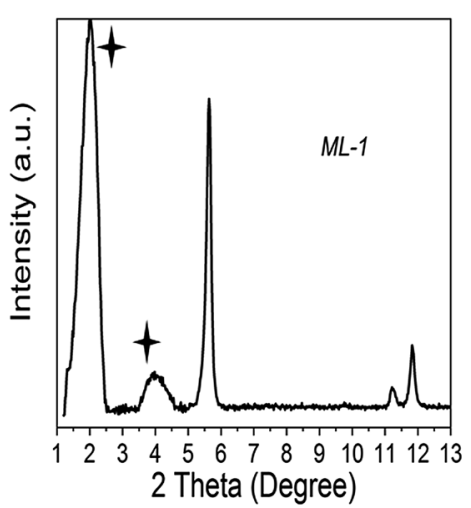

(b)

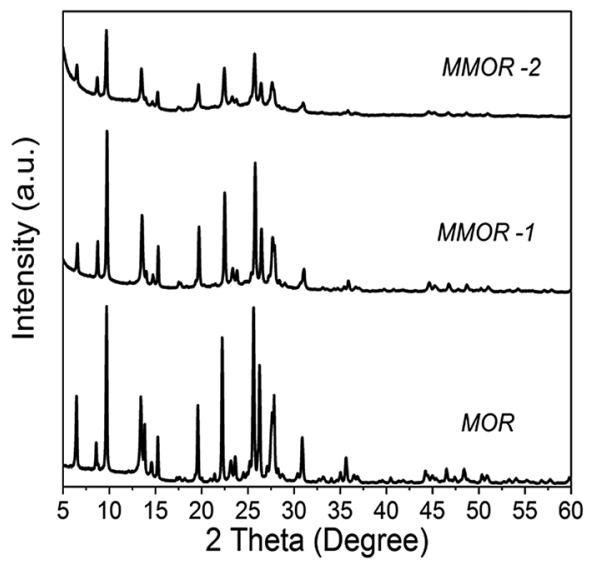

(d)

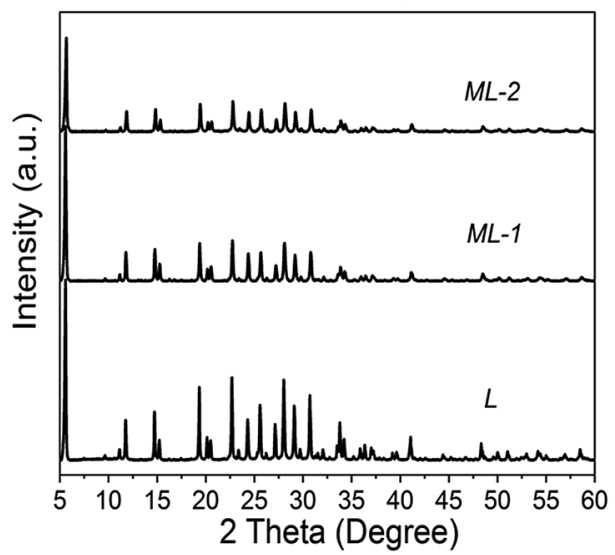

Fig. 3 Low-angle ( $a$ and $c$ ) and wide-angle ( $b$ and d) XRD patterns of the parent and treated MOR ( $a$ and b) and L (c and d) zeolites. The starred peaks indicate long-range ordering in the mesostructured samples.

Table 1 Properties of the parent zeolites ${ }^{30}$

\begin{tabular}{llll}
\hline Zeolite & $\begin{array}{l}\text { Si/Al molar } \\
\text { ratio }\end{array}$ & $\begin{array}{l}\text { Ring size; } \\
\text { pore system }\end{array}$ & Pore size $(\AA)$ \\
\hline FAU & 2.5 & 12-MR; 3D & $7.4 \times 7.4$ \\
BEA & $12.5-150$ & 12-MR; 3D & $6.6 \times 6.7$ and $5.6 \times 5.6$ \\
MFI & $15-40$ & 10-MR; 3D & $5.1 \times 5.5$ and $5.3 \times 5.6$ \\
MOR & 10 & 12- and 8-MR; 1D & $6.5 \times 7.0$ and $2.6 \times 5.7$ \\
LTL & 3.1 & 12-MR; 1D & $7.1 \times 7.1$
\end{tabular}

crystals resulting in the formation of a core-shell type structure consisting of a microporous core and a mesoporous shell. These findings are also supported by recent research, ${ }^{33}$ combining in situ synchrotron XRD and ex situ gas adsorption experiments, which indicates that during the formation of mesopores in faujasites via surfactant-templating the crystalline structure of the zeolite remains largely intact. In contrast, the two-step zeolite recrystallization process reported in ref. 34 is often accompanied by the formation of amorphous silica or silica-alumina. The main difference between these two approaches is the introduction of a surfactant, such as CTAB, during desilication of the zeolite framework. The mechanism proposed by Garcia-Martinez et al. ${ }^{32}$ indicates that as the FAU zeolite is subjected to a basic treatment, the base initiates the hydrolysis of the $\mathrm{Si}-\mathrm{O}$ bonds generating negatively charged defect sites, which attract cetyltrimethylammonium cations $\left(\mathrm{CTA}^{+}\right)$of the surfactant molecule inside the zeolite crystal. As the reaction proceeds, a system of ordered mesopores is produced due to the micelles agglomerations within the individual zeolite crystals. Our data indicate that this process is relatively facile in the large-pore zeolites, FAU, BEA, MOR, and LTL, but not in the medium-pore MFI structure. It should be noted that for the unidimensional pore system of LTL, the formation of mesopores is rather gradual as compared to the more open pore structures, particularly FAU and BEA, thus potentially affording an additional degree of control over the specific features of the pore system in this material. For zeolites BEA and ZSM-5 with a wide range of Si/Al ratios, the amount of mesoporosity generated in BEA is significantly greater than that in ZSM-5 (Fig. 4b and S1 $\dagger$ ). It appears the surfactant species cannot penetrate inside the ZSM-5 crystals due to the small size of the 10-MR pores (Fig. 6). The desilication process for ZSM-5 is more pronounced on the external surface of its crystals under the relatively mild conditions utilised in this work (Fig. S2b $\dagger$ ). Desilication (and dealumination) also takes 

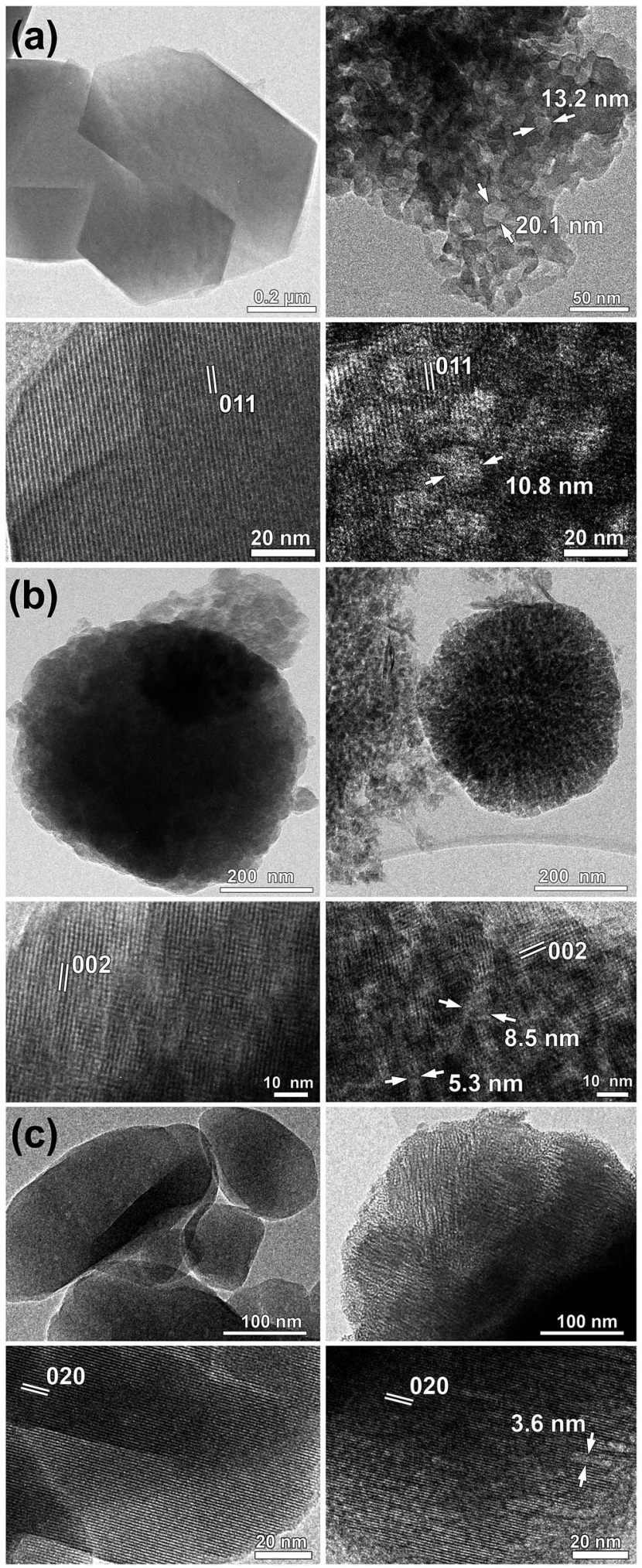

Fig. 4 Bright field low magnification TEM (top) and HRTEM (bottom) images for the parent (left) and modified (right) zeolites: (a) Y, (b) BEA and (c) MOR. Bright contrast pores inside the crystallites are clearly visible and marked with white arrows.
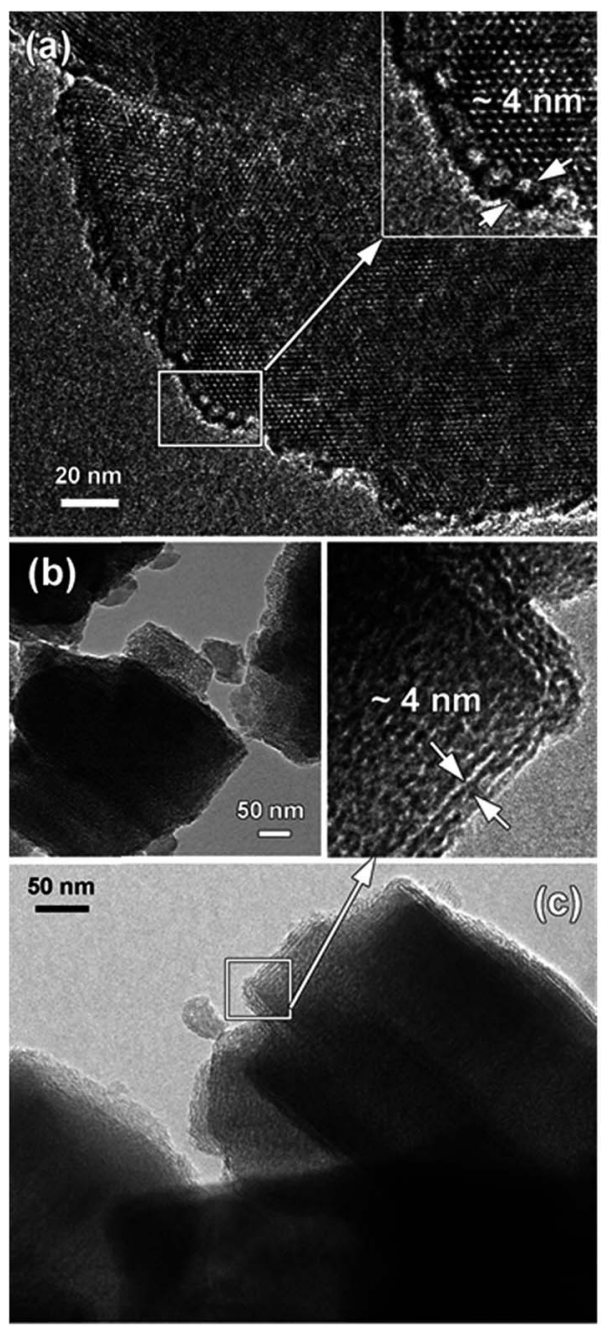

Fig. 5 Bright field TEM and HRTEM images of modified $L$ viewing along two orthogonal directions (a) and (b). Higher magnification TEM image of a single rectangle $L$ particle (c) and enlargement image of the edge (marked with a white rectangle) are given as inserts. The aligned pores (bright contrast) on the surface of the $L$ crystal are observed from both directions.

place on the external surface and the grain boundaries of faujasite and zeolite beta (Fig. 4a and b).

Further evidence of well-defined mesoporosity in the studied large-pore zeolites is provided by the $\mathrm{N}_{2}$ adsorption-desorption data (Fig. 6 and S2c广), which show very different isotherm profiles for the parent (type I) and mesostructured samples (type IV). For all the modified zeolites, a type $\mathrm{H} 4$ hysteresis loop is observed (less evident for ML-1), which is typical of mesoporous zeolites possessing a bimodal pore size distribution owing to the presence of both meso- and micropores. ${ }^{25,35}$ Indeed, a detailed analysis of the connectivity between mesopores and micropores in the mesostructured faujasites conducted using both nitrogen and argon adsorption at different temperatures with hysteresis scanning has demonstrated the presence of interconnected intracrystalline meso- and micropores in these materials. ${ }^{32,36}$ In agreement with the TEM data, MY-1 and MBEA-1 materials exhibit a significant nitrogen uptake at 

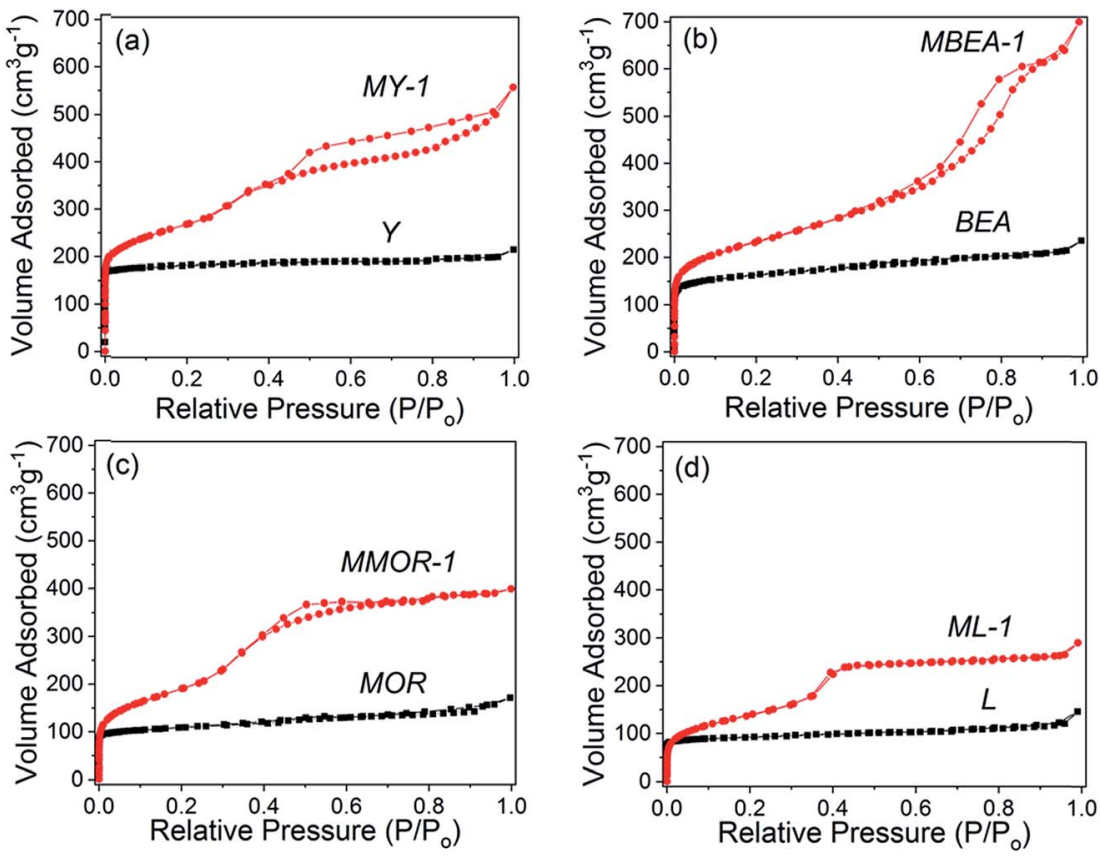

Fig. $6 \mathrm{~N}_{2}$ adsorption-desorption isotherms of the parent and modified zeolites: (a) Y, (b) BEA, (c) MOR and (d) L.

relative pressures higher than 0.5 indicating the presence of larger mesopores as compared with MMOR-1 and ML-1.

Table 2 summarises the $\mathrm{Si} / \mathrm{Al}$ molar ratios and the $\mathrm{N}_{2}$ physisorption results of the studied zeolites. The textural properties, such as the total surface area and the pore volume of the hierarchical zeolites, depend on the concentration of the acid or

Table 2 NMR, XRD and $\mathrm{N}_{2}$ adsorption-desorption characterisation data for the parent and modified zeolites

\begin{tabular}{|c|c|c|c|c|c|c|}
\hline Zeolite & $\begin{array}{l}\mathrm{Si} / \mathrm{Al} \\
(\mathrm{SEM})\end{array}$ & $\begin{array}{l}\mathrm{Si} / \mathrm{Al} \\
(\mathrm{NMR})^{f}\end{array}$ & $\begin{array}{l}\text { Crystallinity } \\
(\%)\end{array}$ & $\begin{array}{l}S_{\mathrm{BET}} \\
\left(\mathrm{m}^{2} \mathrm{~g}^{-1}\right)\end{array}$ & $\begin{array}{l}V_{\text {micro }} \\
\left(\mathrm{cm}^{3} \mathrm{~g}^{-1}\right)\end{array}$ & $\begin{array}{l}V_{\text {meso }} \\
\left(\mathrm{cm}^{3} \mathrm{~g}^{-1}\right)\end{array}$ \\
\hline $\mathrm{NaY}$ & 2.6 & 2.6 & 99 & 855 & 0.33 & 0.04 \\
\hline${\mathrm{MY}-1^{a}}^{a}$ & 4 & 3.1 & 65 & 830 & 0.21 & 0.28 \\
\hline MY-2 & 4.5 & - & 42 & 605 & 0.15 & 0.34 \\
\hline BEA & 19 & 12.7 & 98 & 695 & 0.26 & 0.06 \\
\hline MBEA-1 & 15 & 9.9 & 81 & 740 & 0.2 & 0.12 \\
\hline MBEA- $2^{b}$ & 10 & - & 70 & 810 & 0.16 & 0.25 \\
\hline MOR & 10 & 9.3 & 93 & 488 & 0.20 & 0.03 \\
\hline MMOR-1 & 8.5 & 6.3 & 77 & 600 & 0.14 & 0.18 \\
\hline MMOR-2 $2^{c}$ & 7 & - & 67 & 630 & 0.10 & 0.25 \\
\hline ZSM-5 & 40 & - & 97 & 423 & 0.20 & 0.03 \\
\hline MZSM-5-1 & 35 & - & 90 & 475 & 0.20 & 0.10 \\
\hline MZSM-5-2 ${ }^{d}$ & 32 & - & 85 & 500 & 0.18 & 0.15 \\
\hline KL & 3.1 & 2.8 & 94 & 300 & 0.15 & 0.08 \\
\hline ML-1 & 4.4 & 3.3 & 74 & 380 & 0.11 & 0.17 \\
\hline $\mathrm{ML}^{2} 2^{e}$ & 5.8 & 3.9 & 59 & 490 & 0.07 & 0.28 \\
\hline
\end{tabular}

${ }^{a}$ Treatment of NaY with 6 meq. $\mathrm{g}^{-1}$ (milliequivalent) of citric acid for MY-1 and 9 meq. $\mathrm{g}^{-1}$ for MY-2. ${ }^{b}$ [TMAOH] was $0.15 \mathrm{~mol} \mathrm{~L}^{-1}$ for MBEA-1 and $0.5 \mathrm{~mol} \mathrm{~L}^{-1}$ for MBEA-2. ${ }^{c}$ The high temperature treatment time was $5 \mathrm{~h}$ for MMOR-1 and $15 \mathrm{~h}$ for MMOR-2. ${ }^{d}$ The high temperature treatment time was $9 \mathrm{~h}$ for MZSM-5-1 and $16 \mathrm{~h}$ for MZSM-5-2. ${ }^{e} 0.2 \mathrm{~mol} \mathrm{~L}^{-1} \mathrm{H}_{2} \mathrm{SO}_{4}$ was used for ML-1 pretreatment and $0.4 \mathrm{~mol} \mathrm{~L}^{-1} \mathrm{H}_{2} \mathrm{SO}_{4}$ was used for ML-2. ${ }^{f}$ For zeolites with the ratio of $\mathrm{Si} / \mathrm{Al}>10$, particularly BEA with a large number of $\mathrm{Si}-\mathrm{OH}$ groups, the $(\mathrm{Si} / \mathrm{Al})_{\mathrm{NMR}}$ values are overestimated probably by up to $25 \%$. base used in the treatment and the type of surfactant as well as the contact times. In the basic media, some of the $\mathrm{Si}-\mathrm{O}-\mathrm{Si}$ bonds are opened producing negatively charged sites in the zeolite structure that are balanced by the cationic surfactant species. Thus, the combination of a surfactant and a base is essential for protecting the zeolite structure from excessive desilication. This treatment is successful for medium and high silica zeolites including MOR and BEA ( $\mathrm{Si} / \mathrm{Al} \sim 8-20)$, but not for the low silica zeolites $(\mathrm{Si} / \mathrm{Al} \sim 1-5)$. This can be attributed to the difficulty of breaking the $\mathrm{Si}-\mathrm{O}-\mathrm{Al}$ bonds under basic conditions, and hence, using an extra pre-treatment step with an acid is important. A dilute acid, such as citric or sulphuric acid, can initiate the dealumination process by breaking the $\mathrm{O}-\mathrm{Al}$ bonds. The role of this pretreatment is to create a sufficient number of defects in the zeolite structure, which would facilitate the formation of significant mesoporosity in the acid-treated zeolite through subsequent surfactant-templating. In agreement with the literature, ${ }^{33,36}$ the external surface area and the volume of mesopores both increase with increasing alkali or acid concentration, time or temperature of the treatment, while the micropore volume is largely conserved (see Table 2, Fig. S3 and $\mathrm{S} 4 \dagger)$. Mesostructured zeolites obtained in the presence of CTAB have more than double pore volume and high crystallinity due to the controlled introduction of the intracrystalline mesopores, generally without noticeable formation of amorphous silica or aluminosilicate, which is in contrast to the materials prepared utilising $\mathrm{NaOH}$ or $\mathrm{KOH}$ without the surfactant that are generally characterised by low crystallinity and a broad pore size distribution. ${ }^{37}$

Zeolite acidity, including the type, concentration, strength, and accessibility of active sites, can be characterised by employing FTIR spectroscopy. ${ }^{38,39}$ Pyridine has been used in this study in order to determine the number of Brønsted (B) and 
Lewis (L) acid sites. Our FTIR data demonstrate that the formation of surface defects upon the treatment with basic surfactant solution is correlated with the loss of some Brønsted acid sites and an increase in the L/B ratio (see Table 3, Fig. 7 and $\mathrm{S} 5 \dagger$ ). For all the studied zeolites, this is accompanied by the formation of terminal $\mathrm{SiOH}$ groups characterised by the infrared peak at $\sim 3745 \mathrm{~cm}^{-1}$ (Fig. 7 and S5 $\dagger$ ), in agreement with the data reported previously. ${ }^{40}$ The intensity of the bridging hydroxyl peak at $\sim 3610 \mathrm{~cm}^{-1}$ decreases very significantly for the mordenite samples, whereas for other zeolites, only a modest change in intensity is observed.

Further characterisation of the coordination and local structure of $\mathrm{Al}$ and $\mathrm{Si}$ atoms in the studied zeolites has been conducted using ${ }^{27} \mathrm{Al}$ and ${ }^{29} \mathrm{Si}$ MAS NMR. ${ }^{27} \mathrm{Al}$ MAS NMR spectra of the treated MY-1 and ML-1 zeolites presented in Fig. 8 reveal that the treatments did not result in the formation of octahedral Al extra-framework species with a chemical shift $\delta \sim 0 \mathrm{ppm}$ in these materials after the treatment. The bulk of $\mathrm{Al}$ remains in tetrahedrally coordinated framework positions characterised by the chemical shift values from $\delta=60$ to $\delta=54 \mathrm{ppm}$, which are indicative of the changing local environment of $\mathrm{Al}$ in the different materials. ${ }^{41}$ The amount of extra-framework species $(\delta$ $\sim 0$ ppm) displayed by MBEA-1 increases significantly following the surfactant-templated treatment, whereas for MZSM-5-1 and MMOR-1 only a small increase is detected. In addition, the NMR spectra of the mesostructured FAU, LTL and MOR zeolites show noticeable signal broadening for the framework Al species, which is indicative of the increasing disorder of the local aluminium environment resulting from the pretreatment procedure (see Fig. S6a-d $\dagger$ ). From the comparison of our NMR and FTIR data, it can be concluded that these distorted tetrahedral Al species may be coordinated by Py molecules producing Py-LAS complexes observed in the infrared spectra. This phenomenon, which is particularly evident for the hierarchical FAU and LTL samples, is probably facilitated by the formation of mesopores and enhanced accessibility of the sites resulting from the mesostructuring treatment in the presence of the surfactant.

The Si/Al framework ratio in the studied zeolites has been monitored by ${ }^{29} \mathrm{Si}$ MAS NMR (Table 2). The surfactant-templated modification of zeolites $\mathrm{Y}$ and $\mathrm{L}$ resulted in increasing

Table 3 The concentration of acid sites in the activated ammonium exchanged zeolites

\begin{tabular}{llll}
\hline Zeolite & $C_{\mathrm{B}}, \mu \mathrm{mol} \mathrm{g}^{-1}$ & $C_{\mathrm{L}}, \mu \mathrm{mol} \mathrm{g}^{-1}$ & $C_{\mathrm{L}} / C_{\mathrm{B}}$ ratio \\
\hline $\mathrm{NH}_{4}$-Y & 862 & 48 & 0.06 \\
MY-1 & 689 & 91 & 0.11 \\
$\mathrm{NH}_{4}$-BEA & 409 & 105 & 0.26 \\
MBEA-1 & 397 & 406 & 1.02 \\
$\mathrm{NH}_{4}$-ZSM-5 & 328 & 29 & 0.09 \\
$\mathrm{MZSM}-5-1$ & 281 & 57 & 0.20 \\
$\mathrm{NH}_{4}$-MOR & 864 & 122 & 0.14 \\
$\mathrm{MMOR}^{-1}$ & 337 & 149 & 0.44 \\
$\mathrm{NH}_{4}$-L & 515 & 165 & 0.32 \\
ML-1 & 349 & 286 & 0.82
\end{tabular}

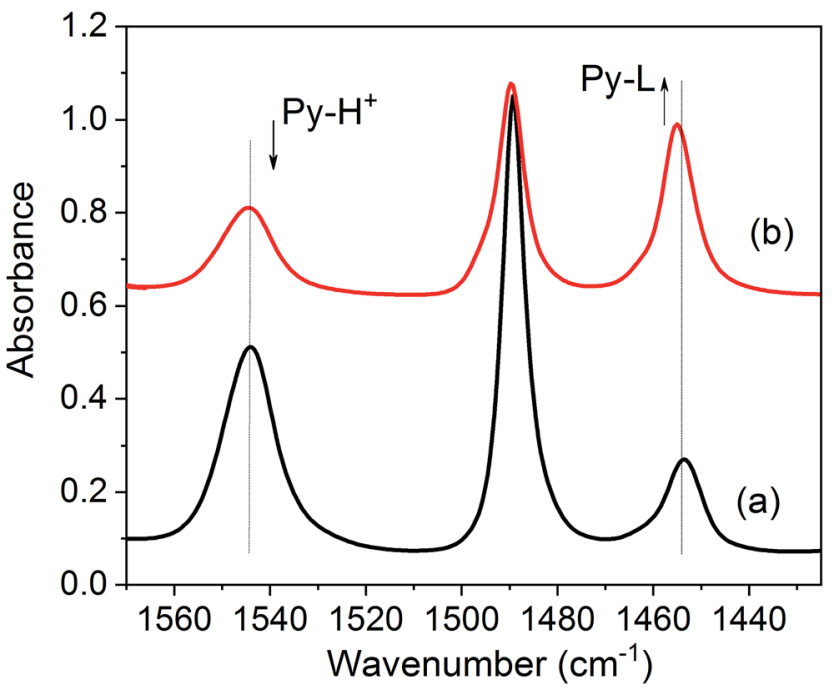

Fig. 7 The spectra of pyridine adsorbed on the parent MOR zeolite (a) and modified sample MMOR-1 (b).

signal intensity for the $\mathrm{Si}(0 \mathrm{Al})$ and $\mathrm{Si}(1 \mathrm{Al})$ sites at $\sim-107$ and $-101 \mathrm{ppm}$, whereas the $\mathrm{Si}(2 \mathrm{Al})$ and $\mathrm{Si}(3 \mathrm{Al})$ signals at $\sim-96$ and $-91 \mathrm{ppm}$ decrease. The generation of $\mathrm{Si}(0 \mathrm{Al})$ and $\mathrm{Si}(1 \mathrm{Al})$ sites during the zeolite treatment is characteristic of dealumination of these materials. In contrast, the ${ }^{29} \mathrm{Si}$ MAS NMR spectra of BEA and MOR zeolites show clear evidence of desilication as the intensity of the $\mathrm{Si}(0 \mathrm{Al})$ decreases following the mesostructuring treatment (Fig. S7†). ${ }^{41-43}$

The TIPB conversion data of both parent and modified zeolites are presented in Table 4 (the product selectivity values are available in Table $\mathrm{S} 2 \dagger)$. It has been shown that the activity of zeolite based catalysts in this reaction is determined by the accessibility of BAS to the bulky TIPB molecules. ${ }^{18,44}$ Our results demonstrate that the TIPB conversion increases on all zeolites following the mesostructuring treatment. The major liquid dealkylation products are 1,3- and 1,4-di-isopropylbenzenes for all the studied catalysts, and a small amount of mono-isopropylbenzene has been detected for both faujasites, which are the most active catalysts as they possess the more open pore systems with the largest pore apertures, and hence, the greatest number of accessible acid sites. Beta zeolites are the second most active pair, which can also be attributed to their open pore structure. Interestingly, a very significant increase in activity is shown by the M-LTL- 1 and M-MOR-1 materials indicating the potential of the applied pore-opening procedure for enhancing the accessibility of the acid sites in zeolites with the unidimensional system of micropores.

In summary, our results demonstrate a successful introduction of uniform mesopores into the crystals of zeolites BEA, FAU, LTL and MOR via surfactant templating. The intracrystalline character of mesoporosity and long-range ordering have been previously confirmed for faujasite type materials using TEM, XRD and adsorption studies., ${ }^{32,45,46}$ Our results extend this work to a number of large-pore zeolites and provide further evidence for the intracrystalline nature of the generated micro-mesoporous materials, rather than the co-existence of 

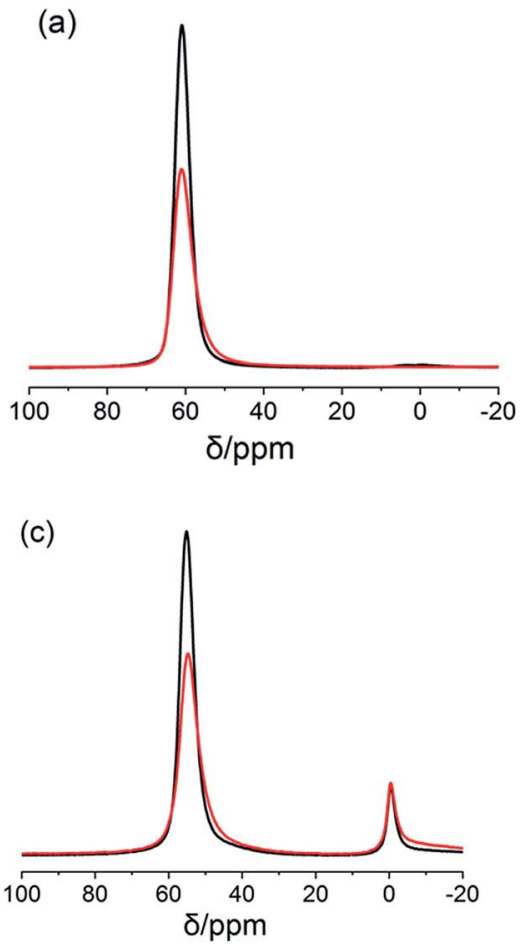

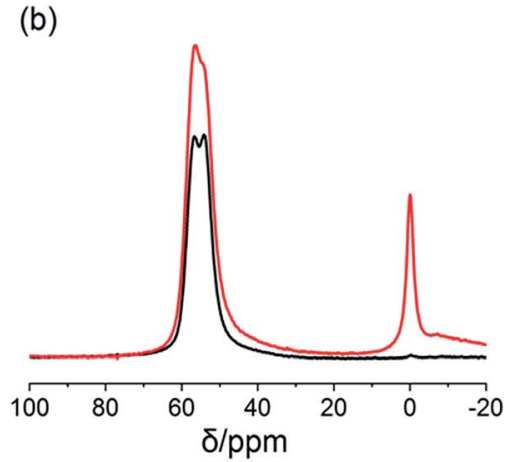

(d)

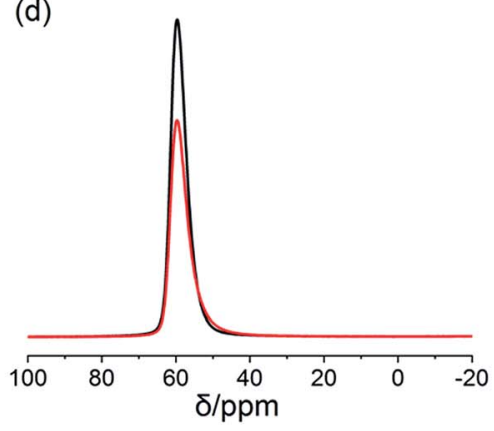

Fig. 8 The ${ }^{27}$ Al MAS NMR spectra of the parent (black lines) and hierarchical (red lines) zeolites: (a) Y, (b) BEA, (c) MOR and (d) L.

Table 4 The conversion of TIPB over the activated ammonium forms of the parent and mesostructured zeolite catalysts

\begin{tabular}{ll}
\hline Zeolite & $\begin{array}{l}\text { TIPB conversion, } \\
\%\end{array}$ \\
\hline $\mathrm{NH}_{4}$-Y & 35 \\
MY-1 & 54 \\
$\mathrm{NH}_{4}$-BEA & 12 \\
$\mathrm{MBEA}^{-1}$ & 17 \\
$\mathrm{NH}_{4}$-ZSM-5 & 2 \\
MZSM-5-1 & 6 \\
$\mathrm{NH}_{4}$-MOR & 2 \\
MMOR-1 & 9 \\
$\mathrm{NH}_{4}-\mathrm{L}$ & 1 \\
$\mathrm{ML}-1$ & 13
\end{tabular}

a microporous crystalline zeolite and a mesoporous amorphous silica in a composite mixture. This is based on direct information obtained from the TEM images of these materials and the shape of the $\mathrm{H} 4$ hysteresis loop observed in nitrogen adsorption-desorption experiments, which is indicative of the interconnected system of micro- and mesopores. Our reaction studies on the transformations of bulky molecules (TIPB dealkylation data reported in Table 4 and aldol condensation results to be presented in a forthcoming paper) also confirm the improved accessibility of strong acid sites in the mesostructured zeolites. It can be concluded that the surfactant species play a key role in the formation of regular intracrystalline mesopores and protection of the zeolite framework against excessive desilication and dealumination during the mesostructuring process, which is in contrast to the treatment of zeolites by a recrystallisation process that can lead to the degradation and amorphisation of the zeolite structure whilst generating a high degree of mesoporosity. In agreement with previous reports, ${ }^{26,47,48}$ our data confirm that the treatment of a zeolite in the presence of an organic surfactant in basic media makes the mesostructuring procedure much more controllable as compared to the severe leaching route utilising inorganic basic solutions (e.g. sodium hydroxide solution) without a surfactant, which generally leads to a significant degradation of the zeolite framework. It is important to note that the presence of a two- or three-dimensional pore system in some zeolites, e.g. medium-pore ZSM-5, may not be sufficient for the introduction of intracrystalline mesoporosity via the supramolecular templating approach of ZSM-5. These types of zeolites, with the pores comprising 10-MR windows, are resistant to the surfactant-templating treatment, and hence, the potential routes to enhancing their intracrystalline porosity are still under investigation. ${ }^{\mathbf{4 9 , 5 0}}$

\section{Conclusions}

Hierarchical materials with uniform intracrystalline mesopores and strong acidity based on a number of industrially important zeolites have been prepared by means of surfactant templated post-synthesis modification of zeolites using a combination of acid and base treatments in the presence of a surfactant, CTAB. This methodology has been successfully applied for the preparation of a variety of well-defined mesostructured materials from a number of industrially relevant large-pore zeolites. To 
the best of our knowledge, it has been utilised for the first time for the LTL structure type. In contrast, the secondary porosity introduced by this method does not show uniform mesopores of tuneable size with 10-MR channels of ZSM-5 crystals. The mechanism of the mesostructuring process is still incompletely understood and the intermediate structures have not been identified. A detailed understanding of the mesostructuring processes would serve as a general guide to allow targeted postsynthesis modification, yielding improved materials having a direct impact on new catalytic applications, particularly involving the transformations of bulky molecules.

\section{Conflicts of interest}

There are no conflicts to declare.

\section{Acknowledgements}

This work was supported by the Ministry of Oil, Oil Marketing Company (SOMO), Baghdad, Iraq under grant SL-144-04A. The authors appreciate the support of the Lennard-Jones Laboratories at Keele University (UK) and ENSICAEN (France) where this study was carried out.

\section{References}

1 R. Rinaldi and F. Schüth, Design of solid catalysts for the conversion of biomass, Energy Environ. Sci., 2009, 2, 610-626.

2 V. Valtchev and S. Mintova, Hierarchical zeolites, MRS Bull., 2016, 41, 689-693.

3 A. Corma and A. Martínez, Zeolites and zeotypes as catalysts, Adv. Mater., 1995, 7, 137-144.

4 R. Srivastava, Synthesis and applications of ordered and disordered mesoporous zeolites: present and future prospective, Catal. Today, 2018, 309, 172-188.

5 D. Verboekend and J. Pérez-Ramírez, Design of hierarchical zeolite catalysts by desilication, Catal. Sci. Technol., 2011, 1, 879-890.

6 M. Silaghi, C. Chizallet and P. Raybaud, Challenges on molecular aspects of dealumination and desilication of zeolites, Microporous Mesoporous Mater., 2014, 191, 82-96.

7 D. Serrano, J. Aguado and J. Escola, Hierarchical zeolites: materials with improved accessibility and enhanced catalytic activity, Catalysis, 2011, 23, 253-283.

8 A. Feliczak-Guzik, Hierarchical zeolites: synthesis and catalytic properties, Microporous Mesoporous Mater., 2018, 259, 33-45.

9 S. P. B. Kremer, C. E. A. Kirschhock, A. Aerts, K. Villani, J. A. Martens, O. I. Lebedev and G. Van Tendeloo, Tiling Silicalite-1 Nanoslabs into 3D Mosaics, Adv. Mater., 2003, 15, 1705-1707.

10 Z. Xue, J. Ma, J. Zheng, T. Zhang, Y. Kang and R. Li, Hierarchical structure and catalytic properties of a microspherical zeolite with intracrystalline mesopores, Acta Mater., 2012, 60, 5712-5722.

11 D. P. Serrano, R. Sanz, P. Pizarro, I. Moreno and S. Shami, Narrowing the mesopore size distribution in hierarchical
TS-1 zeolite by the surfactant-assisted reorganization, Microporous Mesoporous Mater., 2014, 189, 71-82.

12 J. Jiang, J. Yu and A. Corma, Extra-Large-Pore Zeolites: Bridging the Gap between Micro and Mesoporous Structures, Angew. Chem., Int. Ed., 2010, 49, 3120-3145.

13 J. Perez-Ramirez, C. H. Christensen, K. Egeblad, C. H. Christensen and J. C. Groen, Hierarchical zeolites: enhanced utilisation of microporous crystals in catalysis by advances in materials design, Chem. Soc. Rev., 2008, 37, 2530-2542.

14 A. Čimek, B. Subotić, I. Šmit, A. Tonejc, R. Aiello, F. Crea and A. Nastro, Dissolution of high-silica zeolites in alkaline solutions II. Dissolution of 'activated' silicalite-1 and ZSM5 with different aluminum content, Microporous Mater., 1997, 8, 159-169.

15 S. Mitchell, A. B. Pinar, J. Kenvin, P. Crivelli, J. Kärger and J. Pérez-Ramírez, Structural analysis of hierarchically organized zeolites, Nat. Commun., 2015, 6, 8633.

16 M. V. Opanasenko, W. J. Roth and J. Cejka, Two-dimensional zeolites in catalysis: current status and perspectives, Catal. Sci. Technol., 2016, 6, 2467-2484.

17 D. Verboekend, T. C. Keller, M. Milina, R. Hauert and J. Pérez-Ramírez, Hierarchy brings function: mesoporous clinoptilolite and L zeolite catalysts synthesized by tandem acid-base treatments, Chem. Mater., 2013, 25, 1947-1959.

18 Z. Qin, K. A. Cychosz, G. Melinte, H. El Siblani, J.-P. Gilson, M. Thommes, C. Fernandez, S. Mintova, O. Ersen and V. Valtchev, Opening the Cages of Faujasite-Type Zeolite, $J$. Am. Chem. Soc., 2017, 139, 17273-17276.

19 W. Zhang, W. Ming, S. Hu, B. Qin, J. Ma and R. Li, A Feasible One-Step Synthesis of Hierarchical Zeolite Beta with Uniform Nanocrystals via CTAB, Materials, 2018, 11, 651661.

20 B. Ma, X. Yi, L. Chen, A. Zheng and C. Zhao, Interconnected hierarchical HUSY zeolite-loaded Ni nano-particles probed for hydrodeoxygenation of fatty acids, fatty esters, and palm oil, J. Mater. Chem. A, 2016, 4, 11330-11341.

21 J. García-Martínez, M. Johnson, J. Valla, K. Li and J. Y. Ying, Mesostructured zeolite Y-high hydrothermal stability and superior FCC catalytic performance, Catal. Sci. Technol., 2012, 2, 987-994.

22 A. Sachse and J. Garcia-Martinez, Surfactant-Templating of Zeolites: From Design to Application, Chem. Mater., 2017, 29, 3827-3853.

23 M. Milina, S. Mitchell and J. Pérez-Ramírez, Prospectives for bio-oil upgrading via esterification over zeolite catalysts, Catal. Today, 2014, 235, 176-183.

24 A. Al-Ani, R. Darton, S. Sneddon and V. Zholobenko, Nanostructured Zeolites: The Introduction of Intracrystalline Mesoporosity in Basic Faujasite-type Catalysts, ACS Appl. Nano Mater., 2018, 1, 310-318.

$25 \mathrm{~J}$. Y. Ying and J. Garcia-Martinez, Mesostructured zeolitic materials, and methods of making and using the same, US Pat., no. 7589041B2, 2009.

26 J. Pérez-Ramírez, D. Verboekend, A. Bonilla and S. Abelló, Zeolite Catalysts with Tunable Hierarchy Factor by 
Pore-Growth Moderators, Adv. Funct. Mater., 2009, 19, 39723979.

27 D. Serrano, R. Sanz, R. Garcia, A. Peral, I. Moreno and M. Linares, Synthesis of hierarchical Beta zeolite with uniform mesopores: effect on its catalytic activity for veratrole acylation, Catal. Today, 2018, 304, 89-96.

28 Y. Liu, W. Zhang and T. J. Pinnavaia, Steam-stable MSU-S aluminosilicate mesostructures assembled from zeolite ZSM-5 and zeolite Beta seeds, Angew. Chem., Int. Ed., 2001, 40, 1255-1258.

29 D. Serrano, R. Sanz, R. Garcia, A. Peral, I. Moreno and M. Linares, Hierarchical ZSM-5 zeolite with uniform mesopores and improved catalytic properties, New J. Chem., 2016, 40, 4206-4216.

30 C. Baerlocher, L. B. McCusker and D. H. Olson, Atlas of zeolite framework types, Elsevier, 2007.

31 M. M. Treacy and J. B. Higgins, Collection of simulated XRD powder patterns for zeolites, Elsevier, 5th edn, 2007.

32 A. Sachse, A. Grau-Atienza, E. O. Jardim, N. Linares, M. Thommes and J. Garcia-Martinez, Development of Intracrystalline Mesoporosity in Zeolites through Surfactant-Templating, Cryst. Growth Des., 2017, 17, 42894305.

33 N. Linares, E. d. O. Jardim, A. Sachse, E. Serrano and J. Garcia-Martinez, The Energetics of surfactant-templating of zeolites, Angew. Chem., Int. Ed., 2018, 57, 8724-8728.

34 T. Prasomsri, W. Jiao, S. Z. Weng and J. G. Martinez, Mesostructured zeolites: bridging the gap between zeolites and MCM-41, Chem. Comm., 2015, 51, 8900-8911.

35 K. A. Cychosz, R. Guillet-Nicolas, J. García-Martínez and M. Thommes, Recent advances in the textural characterization of hierarchically structured nanoporous materials, Chem. Soc. Rev., 2017, 46, 389-414.

36 K. Li, M. Beaver, B. Speronello and J. Garcia-Martinez, Surfactant-templated mesostructuring of zeolites: from discovery to commercialization, Mesoporous Zeolites: Preparation, Characterization, and Applications, John Wiley \& Sons, 2015, pp. 321-347.

37 N. P. Tangale, P. S. Niphadkar, P. N. Joshi and P. L. Dhepe, Hierarchical K/LTL zeolite as solid base for aqueous phase hydrogenation of xylose to xylitol, Microporous Mesoporous Mater., 2019, 278, 70-80.

$38 \mathrm{~K}$. Hadjiivanov, Identification and characterization of surface hydroxyl groups by infrared spectroscopy, $A d v$. Catal., 2014, 57, 99-318.
39 S. Bordiga, C. Lamberti, F. Bonino, A. Travert and F. Thibault-Starzyk, Probing zeolites by vibrational spectroscopies, Chem. Soc. Rev., 2015, 44, 7262-7341.

40 J. Datka; K. Tarach and K. Góra-Marek, Acidic properties of hierarchical zeolites, Mesoporous Zeolites: Preparation, Characterization, and Applications, John Wiley \& Sons, 2015, pp. 461-496.

41 K. J. D. MacKenzie and M. E. Smith, Multinuclear Solid-State Nuclear Magnetic Resonance of Inorganic Materials, Elsevier, 2002.

42 K. A. Tarach, J. Tekla, U. Filek, A. Szymocha, I. Tarach and K. Góra-Marek, Alkaline-acid treated zeolite L as a catalyst in ethanol dehydration process, Microporous Mesoporous Mater., 2017, 241, 132-144.

43 K. A. Tarach, J. Tekla, W. Makowski, U. Filek, K. Mlekodaj, V. Girman, et al. Catalytic dehydration of ethanol over hierarchical ZSM-5 zeolites: studies of their acidity and porosity properties, Catal. Sci. Technol., 2016, 6, 3568-3584.

44 Q. Lei, T. Zhao, F. Li, L. Zhang and Y. Wang, Catalytic cracking of large molecules over hierarchical zeolites, Chem. Commun., 2006, 1769-1771.

45 S. Lee, C. Jo and R. Ryoo, Tomographic imaging of pore networks and connectivity of surfactant-directed mesoporous zeolites, J. Mater. Chem. A, 2017, 5, 1108611093.

46 D. Mehlhorn, J. Rodriguez, T. Cacciaguerra, R. Andrei, C. Cammarano, F. Guenneau, et al. Revelation on the complex nature of mesoporous hierarchical FAU-Y zeolites, Langmuir, 2018, 34, 11414-11423.

47 X. Jia, W. Khan, Z. Wu, J. Choi and A. C. Yip, Modern synthesis strategies for hierarchical zeolites: bottom-up versus top-down strategies, Adv. Powder Technol., 2019, 30(3), 467-484.

48 N. Suárez, J. Pérez-Pariente, F. Mondragón and A. Moreno, Generation of hierarchical porosity in beta zeolite by postsynthesis treatment with the cetyltrimethylammonium cationic surfactant under alkaline conditions, Microporous Mesoporous Mater., 2019, 280, 144-150.

$49 \mathrm{~K}$. Li and J. Garcia-Martinez, Methods for preparing zeolites with surfactant-templated mesoporosity and tunable aluminum content, US Pat., no. 2017/0190587 A1, 2017.

50 X. Cheng, C. Gerardin, F. Fajula, L. Vaugon, D. Minoux and J. Dath, Mesoporous Zeolitic Material, Method for Making the Same and Use, US Pat., No. 2018/0185827 A1, 2018. 